\begin{tabular}{c} 
International Journal of Scientific World, $6(1)(2018) 38-42$ \\
International Journal of Scientific World \\
SPC \\
Website: $\begin{array}{c}\text { ww. sciencepubco.com/index. } h \text { h } / I J S W \\
\text { doi: } 10.14419 / \text { ijsw.v6il.8677 } \\
\text { Research paper }\end{array}$ \\
\hline
\end{tabular}

\title{
Heritability estimates of egg weight and egg shell weight in Ikenne, Nigeria
}

\author{
John-Jaja Sylvia Alwell ${ }^{1}$, Abdullah Abdur-Rahman ${ }^{1}$, Nwokolo Samuel Chukwujindu ${ }^{2} *$ \\ ${ }^{1}$ Department of Animal Science, College of Agriculture, Babcock University, Ilshan Remo, Nigeria \\ ${ }^{2}$ Department of Physics, Faculty of Physical Sciences, University of Calabar, Calabar, Nigeria \\ *Corresponding author E-mail: nwokolosc@stud.unical.edu.ng; sam31628@gmail.com
}

\begin{abstract}
This study is designed to determine the inheritance pattern of egg weight and egg shell weight of exotic laying chickens at $25,51,72$ weeks and overall mean ages of the birds. For this purpose, thirty eggs were collected daily from the birds continuously for five days of egg production, at each ages 25, 51 and 72 weeks. The total number of eggs collected at each age was 150 and 450 for the total of three age periods. The mean values of egg weight and egg shell weight revealed an apparent increase from 25-72 weeks of age with their corresponding overall mean values. The least square means of egg shell weight at different age groups are significantly different at $(\mathrm{P}<0.01)$ while egg weight was significantly the same since egg shell weight depends on age variance for adequate performance. Statistical analytical system was used to obtain the variance components for the estimation of heritability. High and moderate heritability estimates were obtained when the age variance were included in the computation at different age groups for both traits while high, moderate and low estimates were obtained when the age variances were excluded. The heritability estimates from different egg quality traits were low to high. Since egg weight yielded high estimates at various age groups, the low and moderate heritability estimates recorded for egg shell weight imply that collection of additional records and improvement of non-genetic factors influencing the trait will improve the accuracy of characterizing the inherent ability of the birds.
\end{abstract}

Keywords: Variance Components; Peak Egg Production; Age Variance; Egg Quality Traits; Genetic Potential; Heritability.

\section{Introduction}

Poultry eggs provide means through which the animal protein requirements of the populace can be met. The Nigeria poultry population was put at 135 million comprising 82.4 million chickens ( $11 \%$ which was commercially raised) and 31.9 million other poultry which include pigeons, ducks, guinea fowls and turkeys [1]. Recently, chicken production is increasing due to increased product output per animal, high feed conversion efficiency, improved fertility, hatchability, growth rate, egg yield and meat quality. Poultry keeping requires less land, and most of the poultry species are more prolific than other species of livestock.

Poultry eggs has various uses and contains many essential nutrients; it supports life during embryonic growth and is one of the most nutritious and complete food known to man [2]. The hen's egg consists of the yolk (30-33\%), albumen (approximately 60\%), shell $(9-12 \%), 4 \%$ cholesterol and its yolk has only $16-17 \%$ proteins [3].

Egg consumption has been accepted in Nigeria as a tool for meeting the animal protein intake and ingredient in a balance diet [4], [5]. The overall quality of egg has been considered as the most important trait by the producers and consumers as well for which continuous genetic evaluation of different egg quality traits has become essential in the Nigerian market scenario. Thus, to maintain the superiority in the total egg quality routine genetic and breeding experimentation must be carried out through genetic parameters such as heritability estimates for a number of chicken traits particularly the improved exotic breeds so as to select the best performers with respect to important economic traits through concentrating and enhancing the manifestation of the gene controlling these traits.

Heritability estimates are usually categorized into three classes viz: low $(0-0.19)$, moderate $(0.2-0.39)$ and high $(0.4$ and above $)$ with its values in all classes ranging from $0-1$ or $0-100 \%$. Literature estimates cited in this paper are within the range of low to high [6-11].

Therefore, the aim of this research was to determine the heritability estimates in order to assess the inheritance pattern of various egg quality traits under the influence of age variance in Bovan Nera Black laying chickens.

\section{Materials and method}

\subsection{Location of study}

This research was carried out in the Teaching and Research Farm of Department of Animal Science, Babcock University in Ilare, Ikenne Local Government Area (LGA) of Ogun State, which has its Headquarter at Ikenne Remo. The Local Government Area is bounded $4 \mathrm{~km}$ to the East by Odogbolu Local Government Area (LGA), $5 \mathrm{~km}$ to the South by Ayepe, $10 \mathrm{~km}$ to the North East by Irolu, $4 \mathrm{~km}$ to the North by IIara, $2 \mathrm{~km}$ to the East by IIishan, and $7 \mathrm{~km}$ to the West by Sagamu. The Local Government is located along the transitional forest zone of Southern Nigeria and Guinea Savannah. Ilara is situated between Latitude $6.867^{\circ} \mathrm{N}$ and Longitude $3.717^{\circ} \mathrm{E}$ with an altitude of 235.2 meters above sea level in 
tropical rainforest belt of Nigeria. It has an annual rainfall of $1200 \mathrm{~mm}, 65 \%$ mean relative humidity and $21.4^{\circ} \mathrm{C}$ mean temperature.

\subsection{Experimental birds and management}

Thirty Bovan Nera Black laying birds from the flock of layers in the University Teaching and Research farm were randomly selected based on visual appraisal starting from 23 weeks of age. They were individually housed in labeled separated battery cage. The hen was caged individually in a $0.45 \times 0.3 .5 \mathrm{~m}$ battery cage, and fed commercial diet formulated based on laying birds' requirements NRC [12]. Each bird was fed on average of 131g per head per day with water supplied and libitum for the period of 50 weeks of experimentation and data collection [13]. The detail of the experimental birds and management is found in John-Jaja et al. [13], [14].

\subsection{Experimental design}

Completely Randomized Design (CRD) was used at the first phase to select the healthy hen before laying commenced and visual appraisal at the second phase of design was used for selecting the layers that laid 5-6 eggs within a week from the flocks of Bovan Nera Black layers. Randomization was performed using a random number table, computer, program (i.e. number of treatments and replicates is only limited by the available number of experimental units) [13], [14].

\subsection{Data collection}

Thirty laying birds were randomly selected and housed in labeled separated battery cage. Each egg collected was identified and labeled by the appropriate identification numbers on the egg trays A total of thirty (30) eggs were collected daily from the bird continuously for five (5) days of egg production, at each ages 25,51 and 72 weeks. The total number of eggs collected at each age was 150 for three age periods (25, 51 and 72 weeks) [13], [14].

\subsection{Measurement of egg quality traits}

Each eggs collected was cleaned carefully with a soft damp cloth prior weighing to eliminate faecal and feed smeary which may reduce accuracy by elevating egg weight and consequently introducing bias. The egg weight was measured using a 0.09 sensitive digital scale. These were done by gently placing the egg on the flat surface of the scale ensuring that the scale was set to $0.0 \mathrm{~g}$ before measurement. In order to determine the egg shell weight, the content of the eggs were emptied, the shell was thoroughly washed in running water, dried for two hours at $105^{\circ} \mathrm{C}$ with the shell membrane intact, and weighed on an analytical scale to the nearest two decimal place $(0.0 \mathrm{~g})$. Both petri dishes that was used in weighing the egg contents were initially weighed and the difference in the weights of the petri dish after and before the egg component were taken as the weight of the egg components. After each weighing the petri dishes were washed in clean water and wiped dry before next weighing [5].

\subsection{Statistical metrics}

The least squares means with the corresponding means at different age groups and overall mean and their respective standard error were estimated for egg weight and egg shell weight using Statistical Analytical System program [16]. Statistical analytical system was used to obtain the variance components for the estimation of heritability while the error in the estimation of heritability was calculated using Becker [14].

\section{Results and discussions}

\subsection{Phenotypic least square means and standard error of egg quality traits}

The investigated phenotypic least square means with standard errors of egg weight and egg shell weight are presented in Table 1. The least square means of egg shell weight at 25, 51 and 72 weeks of age are significantly different at $(\mathrm{P}<0.05)$ while egg weight are significantly the same with different magnitude. The least square means of egg shell weight at 72 weeks reported the highest value $7.81 \pm 0.07$ which is significantly lower than $7.62 \pm 0.06$ registered at 51 weeks and $6.36 \pm 0.04$ recorded at 25 weeks of age; and the standard error for different age groups and overall mean age group indicates greater precision. This implies that the environmental effects were large and masked observable genetic variation on the egg shell weight except for egg weight. Similar reports were registered in literature. Paleja et al. [18] observed that egg weight at 32, 40 and 56 weeks of age were significantly the same with the different magnitude of $50.37,51.65$ and 52.43 respectively for white leghorn. Tadesse et al. [19] reported different magnitude of least square means of egg weight for intensive and village production systems for Isa Brown and Bovan Brown having the same significant attributes. However, Khali et al. [20] registered varying magnitude of both least square means of egg weight and egg shell weight with an observable significant difference at $(\mathrm{P}<0.05)$ for Golden Montazah and white leghorn breeds. These observable discrepancies could be attributed to the influence of environmental variance on the traits.

The mean egg weight and egg shell weight revealed an observable variation from one age group to another as presents in Table 1. This could be due to the genetic potential, and the prevailing environmental factor influencing each trait studied and the age of the layers as age is a major factor that influences to a great extent the growth and physiological development of the traits. The mean egg weight registered $55.02 \mathrm{~g}$ at 25 weeks, $62.20 \mathrm{~g}$ at 51 weeks and $63.29 \mathrm{~g}$ at 72 weeks with a corresponding mean value of $60.17 \mathrm{~g}$ for the overall ages of the hen depicting an increasing trend. These reports are similar to $57.78 \mathrm{~g}$ registered by Rath et al. [7] for egg weight at 50 weeks employing white leghorns; $48.1-63.9 \mathrm{~g}$ reported for single Comb and white leghorn at $25-65$ weeks of age obtained by Chen et al. [18]. Sreenivas et al. [11] recorded $50.01-$ $53.89 \mathrm{~g}$ for three pure lines and one control lines of white leghorns at 40 weeks. Blanco et al. [6] obtained $60.3-62.4 \mathrm{~g}$ for white egg lines of Lohmann Tierzucht Gambh at $67-70$ weeks and Brown egg line of Lohmann Tierzucht Gambh at $32-36$ weeks. Sabri et al. [8] registered $50.6-55.6 \mathrm{~g}$ for white leghorn at $26-54$ weeks of age. Paleja et al. [18] reported $45.67-51.33 \mathrm{~g}$ for white leghorn (IWN line) at $32-56$ weeks of age. Kamanli et al. [21] registered $60.3 \mathrm{~g}$ and $61.1 \mathrm{~g}$ for ATAK-S commercial layers hybrids at 52 weeks of age employing incandescent bulb, mini fluorescence and light emitting diodes. Ledur et al. [22] reported $58.0-62.1 \mathrm{~g}$ for white leghorn at $35-65$ weeks of age. Minelli et al. [23] observed $62.0-67.3 \mathrm{~g}$ for commercial layers at $28-73$ weeks of age. Tadesse et al. [24] obtained $58.75 \mathrm{~g}, 60.27 \mathrm{~g}$ and $48.8 \mathrm{~g}$ for Iso Brown, Bovan Brown and Potchetstroom Koekoek breeds at 32 weeks of age. Molnar et al. [25] recorded $63.9 \mathrm{~g}-65.2 \mathrm{~g}$ for commercial layers at $60-80$ weeks of age. Tadesse et al. [19] reported $64.78 \mathrm{~g}, 63.46 \mathrm{~g}$ and 47.79 recorded for Isa Brown, Bovan Brown, Koekoek respectively under intensive production system and 58.92g, 59.32g and 47.53g reported for Isa Brown, Bovan Brown and Koekoek respectively under village production system. Akintola et al. [26] obtained 51.9 - 55.6g for Isa Brown under graded dosage levels of Ovabolin (0ug, 10ug, 20ug and 30ug) at 69 weeks of age. Tumova and Goust [27] reported 56.6g for young ( $22-29$ weeks) and $68.6 \mathrm{~g}$ for old ( 83.99 weeks) Lohmann Brown laying hens, $66.4 \mathrm{~g}$ for young (36-73 weeks) and 7.1.6g for old (64 - 71 weeks) Cobb 500 broiler breeders. Ewa et al. [28] registered 53.30g and 56.72g for Block Olympia and $\mathrm{H}$ and $\mathrm{N}$ Brown Nick breeds respectively between $36-46$ weeks of age. 
However, lower value $42.87 \mathrm{~g}$ was obtained for Iranian fowl at 30 weeks by Begli et al. [10]; Goto et al. [29] recorded 34.84g for Onagadori breed and 41.01g for white leghorn at $20-34$ weeks of age for both breed. Islam and Dutta (30) reported $46.80 \mathrm{~g}$ and 39.83g for Cobb 500 of broiler and Fayoumi breeds at 48 weeks of age. Khalil et al. [20] observed 44.0g and 45.7g for Golden Montazah and white leghorn respectively at 85 weeks. Whereas Petek et al. [31] reported higher values of $74.11 \mathrm{~g}, 73.20 \mathrm{~g}$ and $69.70 \mathrm{~g}$ for commercial brown egg laying hens under effects of non-feed removal molting methods (non-molting control, Barley and Alfalfa respectively). The variation could be attributed to the breed differences, the age of the layers and environmental temperature as recommended by Kitalyi [32].

The bird egg shell weight exhibits a successive increase as the usage of the hen increases. At 25 weeks of age, egg shell weight recorded $6.39 \mathrm{~g}, 7.62 \mathrm{~g}$ and $8.81 \mathrm{~g}$ at 25,51 and 72 weeks of age with a corresponding value of $7.26 \mathrm{~g}$ for the overall ages of the birds. These values agree favourably with the report in literature. Minelli et al. [23] reported $6.00 \mathrm{~g}$ at $28-32$ weeks, $6.16 \mathrm{~g}$ at $47-$ 50 weeks and $6.29 \mathrm{~g}$ at $70-73$ weeks of age. Rath et al. [7] $6.00 \mathrm{~g}$ at 50 weeks recorded for white leghorns. Tumova et al. [33] obtained $6.91-7.81 \mathrm{~g}$ at $28-60$ weeks of age in New Black breed; and $6.50-6.91 \mathrm{~g}$ for litter raised Hisex Brown at 60 weeks. However, Ewa et al. [28] registered lower values $5.05 \mathrm{~g}$ for Black Olympia breed and 5.34g for $\mathrm{H}$ and $\mathrm{N}$ Brown Nick breed at $36-$ 46 weeks of age. Begli et al. [10] observed $4.45 \mathrm{~g}$ at 30 weeks of age for Iranian fowl. Goto et al. [29] recorded 4.75g for Onagadori breed and 5.60g for white leghorn at $20-34$ weeks of age registered for both breeds. Sreenivas et al. [11] reported $4.32-5.12 \mathrm{~g}$ for four genetic groups in white leghorn breed at 40 weeks. Khalil et al. [20] obtained 5.5g for both golden Montazali and white leghorn. These discrepancies could be attributed to the breed differences, the ages of the layers and environmental temperature as recommended by FAO [34].

Table 1: Least Square Means \pm Standard Error of Egg Weight and Egg Shell Weight

\begin{tabular}{llll}
\hline Age & $\mathrm{N}$ & Egg Weight & Egg Shell Weight \\
\hline Overall Mean & 450 & $60.15 \pm 0.31$ & $7.26 \pm 0.05$ \\
& & & \\
Age of Bird & & & \\
25 & 150 & $55.02 \pm 0.40^{\mathrm{b}}$ & $6.36 \pm 0.04^{\mathrm{a}}$ \\
51 & 150 & $62.20 \pm 0.45^{\mathrm{b}}$ & $7.62 \pm 0.06^{\mathrm{b}}$ \\
72 & 150 & $63.29 \pm 0.47^{\mathrm{b}}$ & $7.81 \pm 0.07^{\mathrm{c}}$ \\
\hline
\end{tabular}

$\mathrm{a}, \mathrm{b}, \mathrm{c}$ : means in the same column with different superscript are significantly different $\mathrm{P}<0.05$ and $\mathrm{N}$ is the number of observation.

\subsection{Heritability estimates}

Statistical model 1 was employed to evaluate the heritability estimates of overall ages of egg weight and egg shell weight at 25,51 and 72 weeks when the age of the bird was excluded from the computation and model 2 was used when the age of the bird was included as shown in Table 2.

High and moderate estimates of $0.6908 \pm 0.026$ for egg weight and $0.3189 \pm 0.025$ for egg shell weight using data from overall ages when the age of the bird were included suggesting higher role of additive genetic variance in phenotypic expression of these traits and the low standard error for different age groups and overall mean age group indicates greater precision. These estimates generally agreed with the report in literature. Rath et al. [7] obtained values of $0.443 \pm 0.160$ and $0.223 \pm 0257$ for heritability estimates of egg weight and egg shell weight respectively at 50 weeks of age for white leghorns using half-sib correlation analysis adopted to multifarious species and evaluated using PROC VARCOMP of restricted maximum likelihood (REML) method of statistical package for social science (SPSS). Begli et al. [10] registered $0.45 \pm 0.09$ and $0.23 \pm 0.08$ for heritability estimates of egg weight and egg shell weight respectively at 30 weeks using half-sib correlation analysis adopted to multifarious species and employed restricted maximum likelihood of ASREML software for the estimation of variance component. Sabri et al. [8] reported $0.490 \pm 0.071$ and $0.343 \pm 0.070$ for estimates of heritability of egg weight and shell weight respectively between $26-54$ weeks of age using the method of ordinary least squares analysis of variance. Alpanah et al. [9] obtained 0.50 and 0.54 for heritability estimates of egg weight and egg shell weight respectively at $40-65$ weeks of age using restricted maximum likelihood (REML). Blanco et al. [6] reported heritability estimates 0.49 for egg weight for male white egg lines of Lohmann selected leghorn and 0.65 for egg weight for male Brown egg lines of Lohmann Brown breed between 32 - 36 weeks using mixed procedure of statistical analytical system to a half-sib correlation analysis adopted to multifarious species.

However, low estimates of $0.1277 \pm 0.0091$ and 0.00040 .065 were registered for egg weight and egg shell weight respectively when the age variance was excluded from the computation. This variation could be attributed to the removal of age variance which determines its developmental processes and hence robust the nonadditive gene actions thereby culminating into low, and more accurate estimates of heritability of the traits compared to the report of other genetic researchers [6-9]. Exception of the values of $0.180 \pm 0.122$ and $0.161 \pm 0.079$ obtained for egg weight and egg shell weight for IWI strain of white leghorns using full sib correlation method of mixed model least squares and maximum likelihood (LSMLML) computer software at 40 weeks by Sreenivas et al. [11].

At 25 weeks of age, high and moderate estimates of heritability of $0.7563 \pm 0.0275$ and $0.3776 \pm 0.0453$ were recorded for egg weight and egg shell weight. Theoretically, heritability estimates should decline in magnitude when the age variance was excluded from the computation resulting in decrease in the additive genetic variance. Practically, this trend was not observed in this research indicating minimal influence of non-genetic and permanent environment variance on heritability estimates of the traits of 25 weeks and hence higher to the estimates of egg weight reported by several genetic and breeding researchers [6-8] but lower to the estimates of egg shell weight obtained by Alipanah et al. [9].

However, there was a decline in the heritability estimates from moderate to low as registered for egg shell weight at 51 weeks. This indicates that excluding the age variance from the computation weakens the additive genetic variance as genetic potential reduces with advancing age and hence increasing the non-additive genetic and permanent environmental effects thereby reducing the estimates of the trait compared to the estimates in literature [7-9].

The heritability estimates enhanced from low to moderate as observed for egg shell weight $0.078 \pm 0.0388$ to $0.225 \pm 0.050$ while egg weight experienced a decline from $0.8519 \pm 0.0533$ to $0.7681 \pm 0.0275$ at 72 weeks. This indicates that the environmental effects were large and masked observable genetic variation on egg shell weight at 51 weeks while egg weight experienced same at 72 weeks of age.

Favourably, this trend was observed for shell weight in white leghorn [8], [35]. Grunder et al. [35] estimated heritability of several egg shell weight and economic traits at middle interval of egg production ( $42-45$ weeks of age) and late ( $67-68$ weeks of age) and observed that estimates were almost always higher when measured early compared with late in the laying year. Sabri et al. [8] observed that heritabilities for period 1 ( $26-30$ weeks) were higher although not differing statistically than period $2(50-54$ weeks) for egg shell weight. This indicates that the genetic potential of egg shell weight was well expressed at peak egg production thereby minimizing the effects of environmental factors compared to later periods of the egg laying year in spite of excluding the age variance in the computation as observed in this study. Thus, the high heritabilities at early period of the laying year are advantageous because early selection decisions can be made. Consequently, the heritability estimates of egg shell weight enhanced from low to moderate $(0.2251 \pm 0.0505)$ as observed at 72 weeks of age (see Table 2). The result obtained for the trait is not in agreement with the report of [6], [7] implying that the genetic potential of the trait was not well expressed at 72 weeks of egg production hence enhancing non-additive genetic and permanent environmental effects compared to egg shell weight in literature [7-8], [10], [35]. 
From the results, it could be observed that egg weight is more heritable compared to egg shell weight as the trait recorded high estimates at 25, 51 and 72 weeks of age whereas egg shell weight registered low and moderate estimates of heritability when the age variance were excluded from the computation in order to obtain a more realistic estimates hence identify traits that are more heritable under the influence of age variance.

Table 2: Age Variance, K-Value and Heritability Estimates \pm Standard Error for Egg Weight, Egg Shell Weight for Overall Ages of Birds, at 25, 51 and 72 Weeks of Age for Model 1 Analysis (age of bird excluded), Overall Ages of Bird for Model 2 Analysis (age of bird excluded)

\begin{tabular}{llll}
\hline Age Variance & K-value & $\begin{array}{l}\text { Egg Weight } \\
{ }^{1} \mathrm{H} \pm \mathrm{SE}\end{array}$ & $\begin{array}{l}\text { Egg Shell Weight } \\
{ }^{1} \mathrm{H} \pm \mathrm{SE}\end{array}$ \\
\hline Age Included & 15 & $0.6908 \pm 0.026$ & $0.3189 \pm 0.025$ \\
Age Excluded & 15 & $0.1277 \pm 0.0091$ & $0.0004 \pm 0.0065$ \\
& & & \\
Age Excluded & & & \\
25 & 5 & $0.7563 \pm 0.0275$ & $0.3776 \pm 0.0453$ \\
51 & 5 & $0.8519 \pm 0.0533$ & $0.0780 \pm 0.0388$ \\
72 & 5 & $0.7681 \pm 0.0275$ & $0.2251 \pm 0.0505$ \\
\hline
\end{tabular}

${ }^{1} \mathrm{H} \pm \mathrm{SE}$ represents heritability \pm standard error and $\mathrm{K}$-value is the number of bird per record

\section{Conclusion}

From the findings, it was observed that as the age of the laying bird increases, the magnitude of the least squares means of egg weight and egg shell weight increases. The influence of age variance on heritability estimates of egg weight and shell weight were appreciable as considerable changes in heritability values recorded by excluding the effects of age variance thereby obtaining a more realistic estimates of heritability. However, since all the traits registered high and moderate heritability estimates at different weeks of age, these traits can be improve by mass selection. Improvement in the production environment and non-genetic factors influencing egg production will improve the accuracy of estimating the inherent transmitting ability of the layers in the moderately heritable trait observed for egg shell weight at 51 and 72 weeks and lowly heritable trait reported for same trait at 51 weeks under the influence of age variance.

\section{References}

[1] Rectory Inventory Management. Nigeria livestock resources. Fou Volume Report to Federal Government of Nigeria by Resource Inventory and Management Limited. (i) Executive Summary and atlas (ii) Natural synthesis (iii) state reports (iv) Urban reports and commercially managed livestock survey report, (1992).

[2] T.A. Scott, F.G. Sliver Sides, Poultry Science, 80 (2001) 1245 1248.

[3] United States Department of Agriculture, Egg Grading Manual, Department of Agriculture Washington. USA, pp. 15f (2000).

[4] U.H. Udo, A.S. John-Jaja, Prediction of egg production traits in local chickens using hatch weight. Nigerian Journal of Agricultural, Food and Environment, 10 (2014) 87-90.

[5] F.C. Obioha, A guide to Poultry Production in the tropics. Acena Publishers, Enugu. (1992) 40-48.

[6] A.E. Blanco, W. Leken, D. Ould-Ali, D. Carero, M. Schmutz. Genetic parameters of egg quality traits on different pedigree layers with special focus on dynamics stiffness. Poultry Science. 93 (2014) 2457-2463.

[7] K.P. Rath, K.M. Prasanna, K.M, Bandi, C.B. Nrusingha, Evaluation of different egg quality traits and interpretation of their mode of inheritance in white leghorn. Veterinary World. 8 (2015) 449-452.

[8] H.M. Sabri, H.R. Wilson, R.H. Harms, C.J. Wolcox. Comparison of energy utilization efficiency among six lines of White Leghorns. Genetic and Molecular Biology, 22 (1999) 183-186. https://doi.org/10.1590/S1415-47571999000200008.

[9] O.A.I. Akintola, P.K. Ajuogu, A.O. Aniebo. Effects of Ovabolin (Ethylestrenol) on egg laying performance and egg quality traits in second year layers. Adv Agric Biotechnol 2011; 1:49-52.

[10] H. E. Begli, S. Zerehdaran, S. Hassani, M.A. Abbasi, A.R.K. Ahmadi. Heritability, genetic and phenotypic correlations of egg quali- ty traits in Iranian fowl. British Poultry science, 51 (2010) 710-741. https://doi.org/10.1080/00071668.2010.528750.

[11] D. Sreenivas, M.G. Prakash, M. Mahender, R.N. Chatterjee. Genetic analysis of egg quality traits in white leghorn chickens. Vet World 2013; 6:263-6. https://doi.org/10.5455/vetworld.2013.263$\underline{266}$.

[12] National Research Council Nutrient Requirements of Poultry. National Academy of Science, Washington D.C., 1984

[13] S. A. John-Jaja, A.R. Abdullah, S.C. Nwokolo. Effects of age variance on repeatability estimates of egg dimensions of Bovan Nera Black laying chickens. Journal of Genetic Engineering and Biotechnology; 2016; 14: 219-226. https://doi.org/10.1016/j.jgeb.2016.06.003.

[14] S. A. John-Jaja, A.R. Abdullah, S.C. Nwokolo. Heritability estimates of external egg quality traits of exotic laying chickens under the influence of age variance in the tropics Journal of the Saudi So$\begin{array}{llll}\text { ciety of } & \text { Agricultural } & \text { Science, } & \end{array}$ http://dx.doi.org/10.1016j.jssa5.2016.

[15] S. A. John-Jaja, U.H. Udo. Prediction of egg production traits in local chickens using hatch weight. Nigeria Journal of Agriculture, Food and Environment, 2014; 10: 87-90.

[16] Statistical Analysis System, User's Guide: Statistics, SAS Institute Inc., Cary NC 27513 USA, Scientific and Technical, London, 1999.

[17] A.W. Becker, Manual of Quantitative Genetics. Fourth ed. Academic Enterprises, Washington, USA, (1984).

[18] H.I. Paleja, F.P. Savalia, A.B. Patel, K. Khanna, P.H. Vataliya, J.V. Solanki. Genetic parameter in White Leghon (IWN Line) chicken. Indian Journal of Poultry Science, 43 (2008) 151-154.

[19] D. Tadesse, W. Esatu, M. Girma, T. Dessie. Comparative study on some egg quality traits of exotic chickens in different production systems in East Shewa. African Journal of Agricultural Research. 2015; 10: 1016. https://doi.org/10.5897/AJAR2014.9373.

[20] M.H. Khalil, M.M. Iraqi, M.M. El-Artrouny. Effects on egg quality traits of crossing Egyptian Golden Montazah with white leghorn chickens. Livestock Research for Rural Development. 2013 http://www./wd.org/lrrd25/6/kha/251103htm.

[21] C.F. Chen, Y.P. Lee, Z.H. Lee, S.Y. Huang. Heritabilities and genetic correlations of egg quality traits in Taiwan's chicken. AsianAustralas J. Amin Sci. 193; 6:433-40.

[22] S. Kamanli, I. Durmus, S. Demir, B. Tarim. Effect of different light sources on performance and egg quality traits in laying hens. European Poultry Science. 2015; Doi: 10.1399/eps.2015.109.

[23] M.C. Ledu, L.E. Liljedahl, I. Mcmillan, L. Asselstine, R. W. Fairful. Genetic effects of aging on egg quality traits in the first laying cycle of White Leghorn strains and strain crosses. Poultry Science Association, Inc., 2002; 81: 1439.

[24] G. Minelli, F. Sirri, E. Folegatti, A. Meluzzi, A. Franchini. Egg quality traits of laying hens reared in organic and conventional systems. Italian Journal of Animal Science. 2007; 6: 728.

[25] D. Tadesse, H. Singh, A. Mengistu, W. Esatu, T. Dessie. Study on productive performance and egg quality traits of exotic chickens under village production system in east Shewa, Ethiopia. Afr J Agric Res 2013; 8:1123-8. https://doi.org/10.5897/AJAR2013.6987.

[26] A. Molnar, B. Maertens, B. Ampe, J. Buyse, I. Kempen, J. Zoons, E Delezie. Changes in egg quality traits during the last phase of production: is there potential for an extended laying cycle? British Poultry Science. 2016 https://doi.org/10.5897/AJAR2013.6987.

[27] O.A.I. Akintola, P.K. Ajuogu, A.O. Aniebo, Effects of Ovabolin (Ethylestrenol) on egg laying performance and egg quality traits in second year layers. Advance in Agriculture Biotechnology. 2011; 1:49. https://doi.org/10.1080/00071668.2016.1209738.

[28] E. Tumova, R.M. Goust. Interaction of hen production type, age, and temperature on laying pattern and egg quality. Poultry Science Association Inc. 2012; 91:1269. https://doi.org/10.3382/ps.201101951.

[29] V.U. Ewa, M. O. Otuma, S.I. Omeje, Interrelationship of external egg quality traits of four inbred line chicken stains. Trop. J. Anim. Sci. 2005; 8:23.

[30] T. Goto, J. Shiraishi, T. Bungo, M. Tsudzuki, Characteristics of Egg-related Traits in the Onagoidori (Japanese Extremely Long Tail) Breed of Chickens. Japan Poultry Science Association 2015; 52-81.

[31] M.S Islam, R.K. Dutta. Egg quality traits of indigenous, exotic and crossbred chicken (Gallu, domestics L.) in Rajshahi, Bangladesh. J. Life Earth Sci. 2010; 5:63.

[32] M. Petek, S.S. Gezen, F. Alpay, R. Chibik. Effects of non-feed removal molting methods on egg quality traits in commercial brown egg laying hens in Turkey. Anim. Health Prod. 2007.

[33] A.J. Kitalyi. Village chicken production systems in Africa Rome: FAO; 1998. 
[34] E. Tumova, M. Englmaievova, Z. Ledvinda, V. Charvatova. Interaction between housing system and genotype in relation to internal and external egg quality parameters. Czech J Anim Sci 2011; 56:409-98

[35] Food and Agricultural Organization. Village Chicken Production Systems in Africa by Kitalyi A. J., AGA. Rome. 1998.

[36] A.A. Grunder, R.M.G. Hamilton R.W. Fairfull, B.K. Thompson. Genetic parameters of egg shell quality traits and percentage of eggs remaining intact between oviposition grading. Poultry Science, 1989; 68:46-54. https://doi.org/10.3382/ps.0680046. 